\title{
A propósito del artículo "Utilidad de la angiografía pulmonar por tomografía computarizada en las salas de emergencia de un hospital nacional de EsSalud"
}

On the article, "Utility of pulmonary angiography by spiral CT scan in an emergency room of a national hospital of EsSalud"

\section{Sr. Editor:}

He leído con bastante atención e interés el artículo "Utilidad de la angiografía pulmonar por tomografía computarizada en las salas de emergencia de un hospital nacional de EsSalud" de Román et al. (1), publicado en el último número de la Revista Médica Herediana, donde determinan la utilidad de la angiografía pulmonar por tomografía computarizada cuando existe presunción específica de patologías de arterias pulmonares. En este contexto, me gustaría realizar algunos aportes respecto a la metodología utilizada en el artículo en mención.

Con respecto al criterio de exclusión, Sartori et al. (2), sostienen que la calidad en estudios de imágenes es indispensable para un diagnóstico correcto y fehaciente, la tan sola presencia de algunos artefactos o "pitfalls" en los estudios tomográficos significarían un problema de gravedad, ya que podrían alterar la interpretación de las imágenes obtenidas. El movimiento del paciente (voluntario o involuntario) durante un estudio tomográfico produce un artefacto (3), independientemente del grado de movimiento, este podría condicionar la veracidad de los hallazgos. En este sentido, no queda claro en el artículo de Román A. y col. (1), el motivo por el cual solo las gestantes fueron excluidas del estudio (1), y no pacientes no colaboradores o con enfermedades caracterizadas por movimientos involuntarios.

Asimismo, Román et al. (1), señalan: "La obtención de la angiografía pulmonar fue con respiración suspendida, en dirección caudo-craneal, para visualizar los vasos distales de lóbulos inferiores y minimizar artefactos de respiración en bases pulmonares, y de endurecimiento del haz". En este punto, podría agregar que la respiración suspendida es también para evitar un fenómeno de flujo conocido como TIC (transient interruption of contrast) (4), el cual está asociado al incremento del retorno venoso por la vena cava inferior hacia el lado derecho del corazón durante la inspiración, produciendo un descenso en la concentración del medio de contraste en la zona anatómica de interés, lo cual podría dificultar la interpretación de las imágenes obtenidas (5).

Por otro lado, los resultados obtenidos en el estudio dan muestra de la problemática de los exámenes innecesarios que se vive día a día en los hospitales del país (1). Arce et al. (6), afirman que el uso desmedido e innecesario de los estudios de imágenes está reñido con la ética y requeriría de algún tipo de regulación y que estos estudios deberían ser usados sólo cuando sean imprescindibles y puedan contribuir con el diagnóstico y tratamiento del paciente. Perales et 
al. (7), sostienen que: "Es probable que el aumento de la densidad poblacional médica en el país, en un espacio de mercado restringido, sea determinante del incremento de inconductas en la práctica profesional del médico". Es válida la postura de los autores al afirmar que los exámenes tomográficos como en este caso deberían ser debidamente justificados, conforme a algoritmos diagnósticos (1).

\section{Jorge Porras-Guillermo ${ }^{1, a, b}$}

\section{Correspondencia:}

Jorge Porras Guillermo

Correo electrónico: jorgeporrasguillermo@gmail.com

\section{REFERENCIAS BIBLIOGRÁFICAS}

1. Román Meza A, Alfaro Fernández P. Utilidad de la angiografía pulmonar por tomografía computarizada en la sala de emergencia de un hospital nacional de EsSalud. Rev Méd Hered. 2019; 30(1):27-32.

\section{Réplica de los autores}

\section{Authors reply}

\section{Sr. Editor:}

He recibido la carta que le ha sido enviada previamente a su persona respecto al artículo "Utilidad de la angiografía pulmonar por tomografía computarizada en las salas de emergencia de un hospital nacional de EsSalud" publicado por mi persona y el Dr. Paul Alfaro. Hay que acotar en ese sentido que el lugar donde se realizó esta investigación fue el Hospital Nacional Edgardo Rebagliati Martins, de Nivel 4 en EsSalud, y la problemática mencionada en el artículo hace referencia a lo que se presenta en su Departamento de Emergencias. Al respecto, esta es la respuesta que debo brindarle de los diferentes aspectos indicados por el Lic. Jorge Porras.
2. Sartori P, Rozowykniat M, Siviero L, Barba G, Peña A, Mayol N et al. Artefactos y artificios frecuentes en tomografía computada y resonancia magnética. Rev Argent Radiol. 2015; 79(4):192-204.

3. Costa J, Soria J. Tomografía computarizada dirigida a técnicos superiores en imagen para el diagnóstico. Barcelona: Elsevier; 2015. p. 41.

4. Coulier B, Broeck S. A case of massive transient reduction of attenuation of iodine contrast bolus during computed tomography pulmonary angiography: why and how to avoid it. Journal of the Belgian Society of Radiology. 2013; 96(5):304.

5. Wittram C, Yoo A. Transient interruption of contrast on CT Pulmonary Angiography. J Thorac Imaging. 2007; 22(2):125-129.

6. Arce V, García B, Moenne B, Bosch O. Uso innecesario de exámenes de imagen. Rev chil radiol. 2017; 23(3):140-141.

7. Perales A, Mendoza A, Ortiz P. El Mercado Profesional como Determinante de Inconducta Medica. An Fac Med. 2014; 61(3):207.

Recibido: 09/07/2019

Con respecto al criterio de exclusión de las pacientes gestantes, esto es por el manejo existente en el Departamento de Emergencias, donde cualquier examen de tomografía siempre se realiza salvo contraindicaciones específicas que pueda poseer el paciente, al margen de la sala de Emergencia de donde proceda (tópicos, salas de observación o unidades crítica de emergencia), donde si bien muchos pacientes presentan condición difícil generando algún tipo de movimiento voluntario o involuntario, estos pacientes serán estabilizados y manejados de una forma u otra en la medida de lo posible por el propio médico que solicita el examen tomográfico, quien asume la responsabilidad de solicitárselo en dicha condición. Por ello, el protocolo del examen definido para esta situación en el Servicio de Tomografía es bastante rápido (2,5 seg aprox.), para tratar de contrarrestar al máximo posible artefactos por movimiento.

No se pone en discusión la alteración que pudiese ocasionar el movimiento de cualquier origen 
en cualquier examen radiológico, más aún en la angiografía pulmonar por tomografía computarizada, pero hay que acotar que mucho va a depender de la realidad y el contexto donde se presenten estos pacientes y les soliciten el examen, que en este caso corresponden al departamento de emergencia de un hospital de alta complejidad en nuestro país, y en este caso, en el seguro social, donde definitivamente habrá muchos pacientes en condiciones complejas pero será responsabilidad del médico que evalúa al paciente el solicitar un examen al margen de la condición que éste tenga, y por ende, las exclusiones o negativa de la realización de la prueba que deberán manejarse por parte del tecnólogo médico de radiología asignado en la sala de tomografía 4 ubicada en el Departamento de Emergencia del referido nosocomio para situaciones donde exista contraindicaciones propias que pueda tener el paciente, siendo la principal excluyente el hecho que pueda ser gestante.

Hay que agregar además que sí existiesen situaciones como alergia al medio de contraste el tecnólogo médico de radiología deberá ver ello para que se dé el manejo a nivel de enfermería de forma previa a la realización del examen, y si existiese patología de tipo renal no manejada previamente, el tecnólogo médico de radiología deberá avisar al solicitante del examen que el paciente deberá ser reevaluado por el médico nefrólogo de guardia quien dará el esquema de manejo de forma previa a la realización del examen. De ese modo, estas dos situaciones quedan al margen como posibles criterios de exclusión, puesto que existen formas de manejo institucional para hacer viables la realización de los exámenes de tomografía contrastada. De ese modo, sólo la gestación constituye el principal criterio de exclusión, aparte de los pacientes derivados a la institución sólo para la realización del examen, puesto que no han sido evaluados clínicamente por médicos de Emergencia del propio hospital, es decir, estos exámenes fueron de otros hospitales o unidades de atención.

Sobre la acotación dada por el Lic. Porras acerca del fenómeno de flujo conocido como TIC (transient interruption of contrast) es correcto. Pero cabe decir que los dos artefactos mencionados, tanto los artefactos de respiración en bases pulmonares, como de endurecimiento del haz son los dos principales a considerar y que han perdurado a pesar que este examen ha sido optimizado en la actualidad a pesar del advenimiento tecnológico que ahora permite realizarlo en un tiempo bastante corto (aprox. 2,5 seg de barrido para la angiografía pulmonar por tomografía computarizada), y realizarlo con una cantidad de medio de contraste menor a un estudio contrastado general (sólo $50 \mathrm{ml}$ aprox.), en comparación con una tomografía a nivel toracoabdominal contrastada que requiere en promedio a $1 \mathrm{ml} \mathrm{x} \mathrm{kg}$, parámetros que disminuyen o contrarrestan otros posibles artefactos. Y justamente será la respiración suspendida y adquisición en dirección caudo-craneal la que permita minimizar estos dos grandes artefactos obteniéndose así un adecuado examen diagnóstico.

Lo que sí no se pone en discusión y que fue parte fundamental del artículo presentado, fue el hecho de demostrar que un examen radiológico especializado como la angiografía pulmonar por tomografía computarizada será verdaderamente útil y se justificará su petición cuando exista una presunción diagnóstica específica, y por ende, manejarse de acuerdo a los diversos algoritmos diagnósticos existentes. 